\title{
Immigrant Integration: the Role of NGO's in Lithuania for Upholding Immigrant Assimilation
}

Submitted 05/2020

Accepted for publication 07/2020

\author{
Muraleedharan Vishnu
}

Kaunas University of Technology

Гrossef http://dx.doi.org/10.5755/j01.eis.1.14.26371

Migration and migrant movement are one of the most contested phenomena in the contemporary world due to the large-scale displacement of the people across the globe due to socio-political unrest in the form of wars, internal rebellions, and political upheaval. It led to the scenario of people's movement across the borders in search of better living conditions and safety. However, the aspect of immigration and immigrant integration and assimilation is not a conducive process, and the immigrants must overcome a lot of socio-political hurdles and hardships for the assimilation and integration into the host society. Regarding the actors facilitating immigrant integration, one of the significant actors is the NGOs, which facilitates the integration of the immigrants into society. These facilitate through the mechanisms of advocacy measures. In this scenario, this article tries to find out how the NGO's facilitates immigrant integration and assimilation in Lithuania and what are the mechanisms they employ for immigrant integration and assimilation. The task includes analyzing the qualitative interview conducted with NGO Europos Namai, who are voicing for the rights of immigrants and envisaging measures for migrant integration through their lobbying, education, awareness, cultural integration, and media mechanisms. By analyzing the interview and data sets on immigration in Lithuania, this paper aims to find out how does the NGOs act as a facilitating force for political debates, communication, political decision making, and to create a favorable environment for immigration integration into the Lithuanian society. The primary interpretation is that the third sector organizations play a significant role in the migrant integration into the society, and these possible findings could be made useful for other regions and countries where they are migrant influx and still lack conducive mechanisms for immigrant integration.

KEYWORDS: immigrant integration; lobbying; advocacy; decision making; Lithuania.

Immigration as a phenomenon is one of the most contested issues in modern times and beyond the "political agenda" has penetrated the socio-cultural, economic, academic, and demographic spheres. This, during modern times, has been facilitated mainly due to the high influx of immigration and migrant movements facilitated by globalization together with the human displacement due to wars, rebellion, and social unrest in various parts of the globe. Immigration thus shapes the major discussion in the socio-political spheres, and immigrants tend to migrate to the Western and developed societies due to the higher standard of living and employment opportunities. This facilitates more and more people who intended to emigrate. According to the United Nations (2013) estimated statistics, the intention to immigrate either due to displacement or for better living, there were around 232 million international immigrants, which is $50 \%$ more

\section{Abstract}

\section{Introduction}

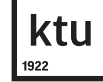

European Integration Studies No. 14 / 2020, pp. 39-54 doi.org/10.5755/j01.eis.1.14.26371 
than during 1990. Among these, most of them (136 million) emigrated to the developed Western nations with most of them (60\%) were from the least developed countries. One of the underlying factors of immigration is the formulation of fear and preconceived notions it creates, especially in the minds of the local population.

Regarding this, the greatest impact has been created by the media through their news reports and articles which visualize the immigrants as threats to the socio-cultural and economic fabric of the society. According to the Transatlantic Trends Survey (2014) report, there is a growing trend of fear as the majority of the people in Europe and North America are impacted by the "underlying fear" about immigration. According to the United Nations (UN, Civil Society Unit), "a non-governmental organization (NGO) is any non-profit, voluntary citizens group which organized on a local, national, or international level. Task-oriented and driven by people with a common interest, non-governmental organizations (NGOs) perform a variety of services and humanitarian functions, bring citizens concern to governments, monitor policies, and encourage political participation at the community level".

The article aims to analyze immigrant integration measures, focusing on the NGO advocacy primarily through advocacy for immigrant assimilation through the advocacy measures of lobbying, media management, cultural awareness, and acquiring national and European funds.

This article sets the following tasks:

1 To address the importance of NGOs in immigrant integration.

2 To evaluate the NGO's advocacy measures, which facilitates immigrant integration in the Lithuanian context.

Advocacy measures of NGOs, in the form of lobbying, media management, cultural awareness, and acquiring national and European funding, can advance proactive measures for immigrant integration in Lithuania. The article depicts the result of the original research, which was carried out by primary data interviews with the NGO Europos Namai, which was founded in 1999, and can act as a significant facilitator for immigrant integration through their project Bukim Pazistami. Also, the article analyzes secondary data by exploring the Facebook discourse of the NGO for half a year from November 01, 2018, until May 02, 2019. The paper developed through the introduction followed by the research gap, theory, methodology, literature review, analysis of the primary and secondary data along with conclusions and references.

Following the commencement of sedentary life and settlement among human beings and the advancement in the socio-cultural sphere initiated the beginning of various socio-cultural and political institutions and along with the public and private institutions, the institution of the third sector and "voluntary organizations" emerged (Brown \& Korte,1989). An NGO is also termed a Non-Profit Organization (NPO) as the term itself states that the intention is not the pursual of financial benefit, but for the welfare of the vested goals for the common good (Grobman, 2002). The significance of NGO's gained prominence during the second half of the nineteenth century and received attention in the United Nations due to the significant humanitarian and social aspect and was mentioned and classified in the UN charter (Mostashari, 2005). An NGO is defined as any entity which seems to be independent of the government regulations and which is not inclined by any political allegiance and affiliations and is not intended for financial gains and out of the criminal activities (Willetts, 2002). In the views of Rahman (2003), the basic characteristics that qualify for being an NGO depend upon five significant attributes, which are "nongovernmental, voluntary, non-commercial, accountable and on political." Even though the research on NGO's is still evolving, and under debate, the main classification of NGO's categorizes into operational NGO's and advocacy NGO's (Willetts, 2002). 
Regarding this classification, the major difference is that the operational NGOs will facilitate the funding for carrying out the assigned and intended works. In contrast, the advocacy NGO's even have a similar role will carry out activities for the betterment of the attributed interest of the organizations through advocacy measures (Mostashari, 2005). However, these are classed as "third sector" organizations in which the public and private sectors termed as a first and second sector (Korten, 1990; Mostashari, 2005).

In holistic terms, the NGOs broadly termed as "third sector" or "non-profit" organizations, which classifies those which are outside of the first and second sectors (Pharr, 2003). It consists of individuals and organizations which are outside of the governmental and market considerations and intended to work for the welfare of the specific and targeted groups (Brown et al., 2000). It enables the interaction and association of people who have similar aspirations and allows them to cooperate for the fulfillment of those aspects, which can bring common good (Pharr, 2003). It contrasts with the membership of both the public and private actors in which the membership is either based on monetary consideration or a citizenship aspect (Olson, 2009). It also enables them to be a part of different groups that incline their orientation.

In contrast, in the public sector, it is difficult to be a member of more than one political group. It enables individuals to access the resources on a broader aspect, thereby facilitating allocation for social welfare (Whitley, 1999). It is a significant aspect as unlike the members of the political organizations who have broader reach and influence over the resources, the members of the third sector lack the influence to avail themselves of broader resources, but with greater numbers and organizational strength through coalition aspect, they are enabled to have access and control over resources (Perez-Diaz, 1998). In the sociological and political context, the aspect of social movements classified on the aspect of its reach and impact depend on whether their activities are national or global. In this context of this paper, immigration is perceived as a social movement with a global scale that has implications both at the international and national levels, especially of the receiving nations (Minkoff, 1997; Ericson \& Doyle, 1999).

Lithuania is a young European Union Baltic nation, and since 2004 has received a significant amount of immigration due to the accession and membership to the EU. This creates a situation for the need of immigrant integration mechanisms. It shows the significance of this article as there is a lack of considerable research on the aspect of immigrant integration measures in Lithuania by the NGO's with their advocacy measures. The relevance of this paper is that unlike other countries and regions where the third sector and its activities have been deeply researcher, in the Lithuanian context, it is still an unexplored area and under-researched. One of the significant researches carried out in this field was conducted by a group of researchers who published a monograph titled "Undiscovered power: A map of Lithuanian civil society". It was formulated using various national and European databases and explored the impact and reach of civil societies in the Lithuanian society, public, and impact on governmental policies. It thus generally covers the attributes of NGO's without explicitly exploring the effect of specific categories of NGO's as per their characteristics (Ziliukaite, 2006).

Another aspect regarding the relevance is the lack of proper scientific study looking at the element of human rights NGO's in Lithuania. Most of the studies which were conducted are having a general attribute like the above-stated monograph and look at the aspect of push and pull factors of emigration rather than push and pull factors of immigration. While one study titled "Mapping of social orientation: the case of Lithuania" looks at the aspect of immigrant integration measures of the NGO's looking at the element of European migration fund for asylum seekers and the measures for skilled immigrants. However, it did not comprehensively cover the actions of NGO's for immigrant integration through the media measures and new media mechanisms, the integration activities 
conducted at the grass-root level and to remove the barriers using the NGO activities. Thus, in this context, this paper tries to comprehensively explore all the attributes of the human rights NGOs in Lithuania looking especially at these measures of NGO Europos Namai (Zibas, 2018).

NGO's face considerable pressure, especially in societies that have higher inclinations towards socio-cultural norms (Lewis \& Kanji, 2009). It is particularly significant in the case of Lithuania due to the former Soviet occupation, which creates a lack of trust of the local population towards foreigners. Another considerable challenge is governmental control in NGO management, especially in totalitarian, authoritative, dictatorial, and democratic governance with lesser transparency (Mukasa, 1999). Another significant challenge is the availability of dedicated volunteers, who can demonstrate an aspiration for the common welfare and staff with a dedication to work in the third sector with enhanced commitment with lesser pay structure in comparison to the public and private sector (Vilain, 2002). The growth and momentum attained by the NGO's led to the convinced notion among the public actors and practitioners that the NGO's are in the core of a "quiet revolution" (Fisher, 1997). It seems relevant due to the growth of various humanitarian NGOs in Lithuania, especially the Bukim Pazistami, which was founded in 1999. It makes them visualize them as social actors who are inclined to do common "good" without the attribution of profit or political affiliation. It makes the NGO the preferred option of major international charitable and welfare organization, which enables them to reach out to the needy by allocating the funds to the NGO thereby enabling to rectify the odds of the social and economic system (Hulme \& Edwards,1997). This aspect and the effective implementation of the intended projects enable more and more actors to trust NGOs as the prominent actor to channel facilities for the fulfillment of socio-economic goals (Keck \& Sikkink, 2014). Another significant aspect of the operation of NGOs is the behavioral attribution of the staff and employees as, unlike the public and private sectors which are often driven by professional and monetary benefits, NG's are inclined more by social commitments and the goal of the betterment of the society (Hulme \& Edwards, 1997). Hence this article explores the advocacy measures of the NGOs for immigrant integration in the Lithuanian context.

Theory of the research: Network institutionalism
According to Malhorta (2000), NGOs need to viewed as the significant social actor, which facilitates social interaction, which was limited by the other social actors due to the lack of social and human resources, which facilitates an imbalance in the social sphere. One of the significant drawbacks regarding the NGO research in the academic arena is the lack of research on the theoretical significance of NGO relations to other social actors and its impact on the social setting. This article explores the NGO's interaction with other social actors and the measures for interaction in the context of immigration by looking through the lens of network theory. Network theory explores the aspect of networks and interactions between the public, private, and third sectors. It explores the diversity of interest and conflicting nature of these enterprises and the point of cooperation and amicability among them. This article explores those natures of these actors, which enables collaboration among them despite their differences and conflicting nature because of the dependency on the "resources," which can be beneficial for immigrant integration (Ohanyan 2008). These are the financial, institutional, and human resources that facilitate immigrant integration, which was enabled by cooperation between NGOs and public and governmental actors. These are channeled through advocacy measures such as lobbying, media management, creating public awareness, and influencing public actors for the acquiring national and European funding for immigrant integration. From the sociological point of view, network theory is stated to be a mechanism that will enable the actors to have a meaningful interaction among themselves more intensively than with the actors from outside the "organizational" structure (Wooten \& Hoffman, 2008).

However, the main limitation regarding the network mechanisms is the lack of its "egalitarian" nature and the imbalances in the allocation of the resources between various actors. From this 
article's perspective, this is viewed as the main constraint for the NGOs in accomplishing their intended actions. This aspect is overcome through the mechanism of advocacy activities through which the NGOs convey their intentions to the public and private actors, thereby facilitating the allocation of resources. The theoretical aspect of the network theory has an interdisciplinary nature and has its linkage to "sociology, anthropology, political science, and public administration." The enhanced globalization aspect, with the weakening of national administrative structures and the significance of the international institutions and market forces, along with the rise of third sectors leads to the growing significance of the network theory on the global scale (Swank \& Duane, 2002). Thus, network theory was able to rectify the odds in the global and national administrative and network mechanisms (Reinicke et al., 2000). Increasing immigration into the developed Western nations has led to the growth of humanitarian NGOs which facilitates immigrant integration and assimilation measures by coordinating with other actors in the institutional network by influencing the policy formulation and assisting in policy implementation, which depicts the role of NGOs in overcoming the "governance" and administrative vacuum", which were created due to the growth of transnational institutions and due to the impact of global governance (Marsh, 1998). One of the significant aspects of the network mechanism is to overcome the odds of policy and administrative machinery, which is facilitated by NGOs. It is accomplished through the network mechanism of the NGO's which have a wider reach and grassroots implications. It enables the penetration of the policy benefits to the lower levels of the social strata, benefiting the weaker and more deprived sections of society which are largely neglected due to the lack of proper administrative and managerial mechanisms of the public institutions, together with the bureaucratic constrain and "hierarchical" aspects (Ebrahim, 2005; Lindenberg \& Bryant, 2001). Due to this, the article considers the context of network theory, which connects the NGO measures for immigration integration through the network interactions with public and private actors such as the government, media, private sector, and host community.

\section{Methodology}

NGOs through their advocacy measures, play a prominent role, along with policy actors, for the facilitation of the immigrant integration measures. They enable communication between the immigrants and the local communities, which enhances trust between these constituencies. Lithuania is a young independent Baltic country in the European Union with a population of 2.79 million. In the Lithuanian context, immigration is a recent phenomenon, unlike other western European countries, due to the previous Soviet occupation, and the phenomenon of immigration started from 2004 after the membership of the European Union (EU).

For analyzing the advocacy measures of the NGO, the paper classifies the advocacy activities into four aspects, such as lobbying, cultural awareness, media orientation, and acquiring the funding for facilitating immigrant integration activities. These are explored by using primary data by interviewing the coordinator of the NGO Europos Namai who oversaw the integration project Bukim Pazistami. Also for analyzing the communication aspect of the NGO, Facebook discourse of the NGO has been taken for half a year from November 01, 2018, till May 02, 2019, which identifies the media mechanism for disseminating immigrant perceptions by sharing the immigrant testimonies with the immigrant integration seminars, discussions and debates in various municipalities of Lithuania covering educational institutions, public institutions, youth centers, and libraries.

\section{Identifying the advocacy measures of the NGO's for immigrant integration}

Immigration is one of the most contested phenomena in Western societies due to the large inflow of people from developing and underdeveloped nations, caused by a variety of socio-economic and

Literature review 
political scenarios. It led to a situation of immigrant crisis and the need for immigrant integration. Unlike other Western societies in which the issue of immigration is a long-debated issue due to the higher volume of immigrants for decades, this is a recent phenomenon in Lithuania due to the younger aspect of the nationhood and its more recent accession to the EU. It led to the immigrant arrival from the period of 2004 , and it is necessary to identify the immigrant integration measures from the Lithuanian context. Therefore, this article analyses the immigrant integration measures in the Lithuanian background, looking at the NGO advocacy and integration measures.

With regard to advocacy, NGOs are organizations that assist deprived sections of the society who cannot fulfill socio-cultural requirements alone. Immigration and immigrant integration are one such section of society that requires assistance for assimilation into the society, especially since the measures are taken by other social actors like the government appear to be inadequate (Parker, 2003). This is mainly due to the different social and cultural contexts of the immigrants, for which integration needs to be facilitated by another party. NGOs, through their advocacy activities, facilitate interaction between different stakeholders, thereby enhancing the relationship for achieving the goals of the organization. It is accomplished when the subject of interest of the NGO's whose voices were less heard due to the lack of bargaining powers which sideline their attention towards the public and private forces in the society. It brings the NGO to the frontline for voicing these needs (Stromquist, 1998; Meyer, 1999). They also intervene when there is a lack of consensus with public actors and those implementing such policies, which leads to the breakdown of these mechanisms which hampers the interest of the weaker sections (Reisel \& Sama, 2003). NGOs pursue these through various advocacy measures such as "lobbying," creating consensus with the policymakers, providing an expert legal and public opinion, staging "conferences, demonstrations." In the context of immigration, these advocacy measures seem to have a great impact, as through these measures the NGO's effectively lobby for the immigrant's policy formulation and implementation and through the mechanisms of conferences, public events they orient the local communities and educate them regarding the significance of immigration and to remove the negative perceptions and stereotypes thereby facilitating immigration (Hudson, 2002). Thus, through these measures, the NGOs rectify the odds in the social system and provide relief to deprived sections of the society (Vachani \& Smith, 2004).

Regarding the advocacy activities of the NGOs, these are classified as "insider" and "outsider" activities. Insider activities are through those measures in which the NGO tries to influence policymakers to make progressive and desirable policy decisions for deprived sections of the society. In contrast, through outsider activities, they try to influence and educate the public regarding various social issues and to make a positive public approach towards those issues. These measures enable NGOs to create an overall impact in the social sphere regarding the objectives they targeted towards by making their influence in the public, private and social system (Peterson, 1992; Kolk \& van Tulder, 2002). A significant aspect of the NGO mechanism is the influence they exert on the "institutional" mechanism in the form of advocacy measures such as "pressure group" lobbying, demonstrations, and protest mechanisms. These measures enable the NGOs to influence the institutional settings of the public and private institutions, thereby directing towards the measures which align with the ideals of the NGO mechanisms. These have a significant impact on various policy measures. Regarding immigrant integration measures, these pressure and lobbying tactics of the NGOs have greater relevance as it enables them to lobby for favorable public policies for immigrant integration measures and policies for enhanced immigrant intake and assimilation. Also through these measures, they were able to formulate the perception of the local population to have an accommodative mindset towards immigrants and to orient the private actors towards the benefits of immigrant accommodation into employment which can 
harness the immigrant skills and benefits from the knowledge sharing for the wellbeing of the community (Mahon \& Waddock, 1992).

These measures by the NGOs enable a situation of "mutual dependence" between the public, private and third sectors, which leads to progressive aspects in the social, cultural, economic, political, and demographic sphere, especially concerning immigration (Perez-Diaz, 1998). This mutual dependence seems particularly relevant in the times of globalization and the conceived notion of a global village that facilitates global movement (Sanderson, 2002). This enhanced social movement in the phenomenon of globalization also leads to disturbances in the social, cultural and environmental sphere in which the perceived presence and cooperation between the three sectors can mitigate the dangers of degradation and can enhance sustainability (London \& Hart, 2004; Douglas \& Judge, 1995). Lobbying is perceived as one of the significant advocacy measures of the NGO through which they seek to influence the legislators and policymakers for policy measures that suit the objectives of the organization (Beyers, 2008; Kluver, 2011). The act of lobbying will either be done solely by an NGO or in alliance with other NGOs who have the same objectives regarding a topic (Beyers et al., 2008). The central aspect which distinguishes the NGO from other sectors is that it is entirely out of the interference and management of the government and semi-governmental institutions and is instead managed by individuals and entities who have an orientation towards a particular issue of the society and seeks to make changes with the advocacy measures (Lewis, 2010). Due to these characteristics, they are termed "non-profit" entities (Willetts, 2010). Another characteristic which distinguishes NGOs is that other than the governmental control, it eliminates other actors such as "religious" organizations, "academic" entities, "political" organizations, and "criminal" entities and "business" organizations (Charnovitz, 1996). In the case of immigration, this seems relevant as regarding this article as the lobbying for immigration and immigrant integration has been carried together by different NGOs such as Europos Namai, Red Cross, Caritas, and Diversity Group.

\section{Case Study: Advocacy mechanisms of Bukim Pazistami}

As a newly independent country in the Baltic region from the Soviet occupation in 1991, the establishment and the development of NGOs is a recent phenomenon. These circumstances led to a challenging situation for NGO measures, especially for the advocacy and grassroots movements. Although the phenomenon of NGOs is broadly defined, this article explores explicitly the NGO's who are focusing on immigrant rights and their integration. However, unlike other Western European countries which have a large network of NGOs specialized in the human rights movement due to the large-scale immigration and refugee crisis, this is not particularly visible in Eastern Europe, especially the Baltic region, due to the late independence of the Baltic countries and their accession to the European Union.

Regarding international immigration, immigration to Lithuania is a recent phenomenon and started mainly after EU membership on May 01, 2004. Lithuania has begun attracting international labor and skilled migration, especially from other Eastern European countries such as Belarus, Ukraine, Russia, and recently from developing countries in Asia, Africa, and Latin America. Figure 1 shows the number of immigrants in Lithuania from 2004-2018. Regarding the prospective aspect of immigration to Lithuania is that of being an EU country that facilitates the immigrant's free movement across the European countries to have market access for employment and skill development. Another aspect is the higher standard of the Lithuanian educational institutions, which provides quality education with the European framework and accreditation, which attracts international students from across the globe. It enables students to have a European accredited educational qualification at an affordable cost and access to the EU markets. Also, the reasonable cost of living allows immigrants with a lower economic background to sustain themselves in 
Figure 1

Number of Immigrants in Lithuania from 2004-2018

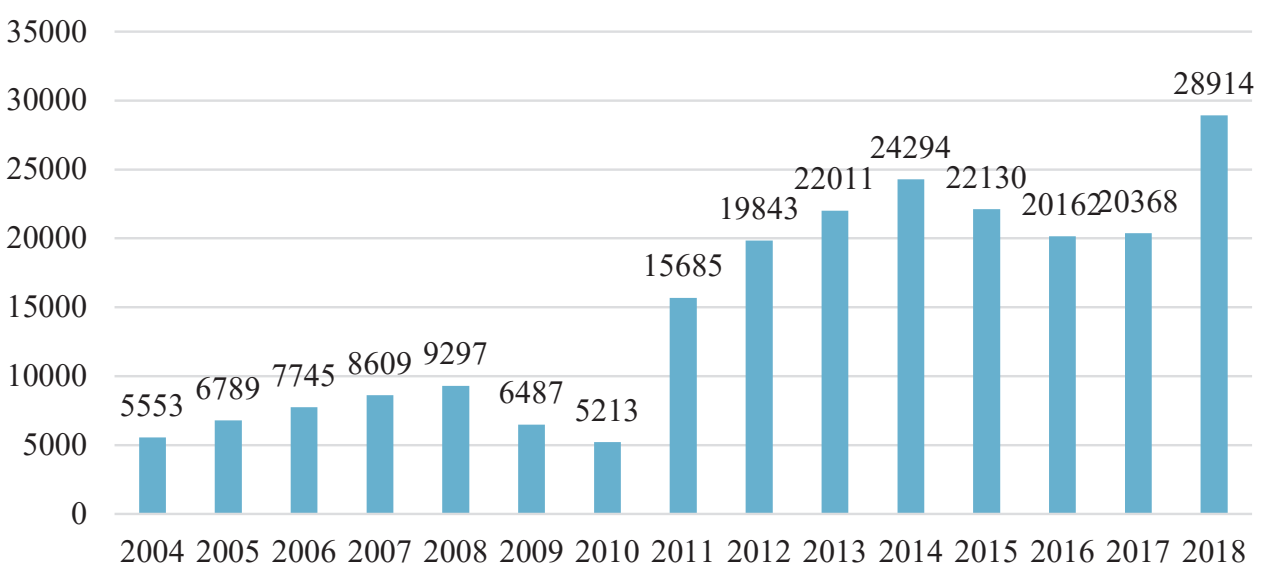

Source: Europos Migracijos Tinklas.

Lithuania with access to the European market.

The significant challenge for immigrants is the lack of local language skills for employment, as most of the jobs require proficiency in Lithuanian together with English or Russian, which presents challenges for the immigrants. Also, the recently integrated mechanism and the lack of contact with the other parts of the world makes the local population have hesitation for close cultural connections. In this regard, it is the NGOs who are focusing on immigrant integration play a significant role in immigrant assimilation and cross-cultural integration.

The role of advocacy has been facilitated by NGOs in Lithuania by creating social and cultural awareness and integration about other cultures and their practices, advocating for humanitarian development for immigrant intake through socio-cultural events, thereby familiarizing the aspects of different cultures. These are achieved through socio-cultural activities in public places, including recreational centers and libraries, schools, and educational institutions, and by conducting classes for imparting local language skills and providing counseling and emotional assistance for immigrants. Another aspect is the use of lobbying by NGOs to enhance the immigrant's accessibility for the entry by conducting lobbying with the legislators and pro minded institutions and to access national and EU funds for facilitating immigrant integration.

The Bukim Pazistami project under the European Namai from 2017-2019 works under the umbrella organization NGO Information Support foundation, which is the broader organization that acts as a coordinator for various NGO activities in Lithuania, which covers all the broader themes of NGO management. Regarding immigrant integration, in close cooperation with Caritas, Red Cross and Diversity Group it makes proposals and implements projects under the banner "Lithuanian identity-mosaic of nations," which is funded by the EU Asylum, Migration and Integration Fund. It enables the humanitarian NGOs in Lithuania to work together on a platform for social awareness regarding the displacement and immigrant crisis across the globe, the benefits of skilled immigration, cultural diversity, the richness of immigration, and the need for immigrant intake under the EU platform as a member state.

\section{Findings of the study}

To understand the role of NGOs in immigrant integration in Lithuania, an interview was conducted with the coordinator of Europos Namai, who is also the lead organizer and communication manager of international cooperation of the cultural integration activities of the NGO known as 
Bukim Pazistami. The interview focused on the role of NGOs in Lithuania regarding advocacy, lobbying, and measures envisaged for immigrant integration. According to the coordinator, the significant measures of the NGO regarding immigrant integration classified into four measures, such as lobbying, cultural awareness, media orientation about the immigrants, and acquiring national and European funds for integration measures. Figure 2 below shows the advocacy activities of Europos Namai.

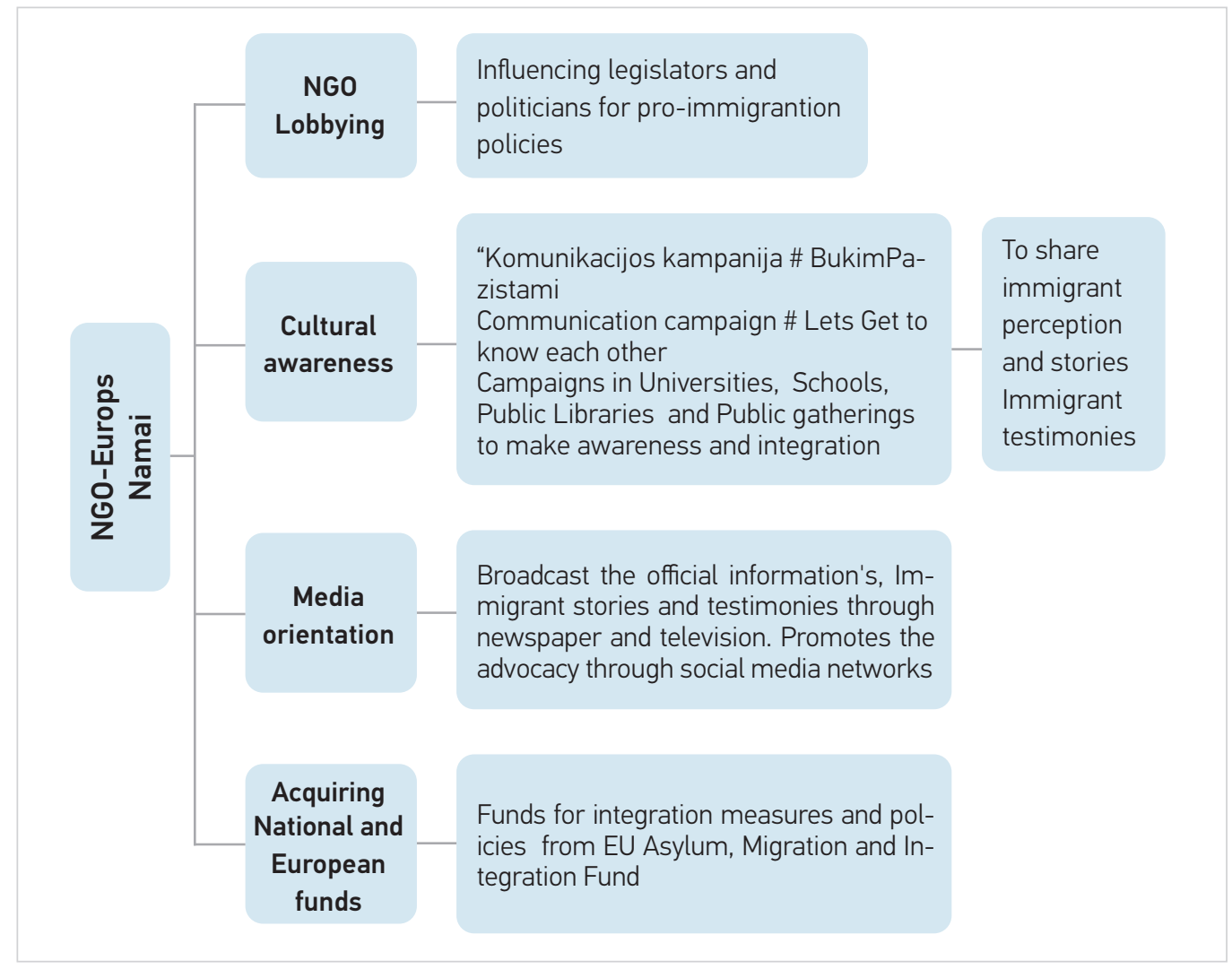

Source: Author

Regarding the NGO measure for the lobbying, the coordinator was not implicitly citing the efforts for lobbying and to whom the lobbyist mainly approaches and what means they employ for it. However, she mentioned that the main lobbying activities of the NGO are done on a coordinated basis together with other major humanitarian NGOs like Caritas, Red Cross, Diversity group. It enables NGOs to find consolidated measures from the governmental authorities for immigrant integration. The second mechanism is the measures envisaged for creating cultural awareness regarding the immigrants to facilitate amicable integration in society. As Lithuania is a young country and has a lack of proper exposure to outsiders, unlike other Western European countries, it finds it difficult for the appropriate cultural integration of the immigrants and to embrace the immigrant cultural aspects. Also due to the negative media-driven perception of the immigrants, especially refugees and asylum seekers, concerning socio-cultural and religious inclinations, a sense of fear is created among the host societies especially in the case of Lithuania as according to the NGO "A large part of the Lithuanian population would not want their neighbor or co-worker to be a foreigner, but only a few of them know or have interacted with them. It is because of the lack of knowledge and personal experience that there is a fear of others".
Figure 2

Advocacy activities of Europos Namai 
In this context, the NGO through the cultural awareness program aims to facilitate the communication and interaction between the locals and the immigrants. It is facilitated through the program "Komunikacijos kampanija \# BukimPazistami," which means Communication campaign \# Let's Get to know each other in which the NGO shares the experience, perception, and insights of immigrants about Lithuania. Also, it depicts how they feel and differentiates their experiences between here and their home country and how they make accommodations for the cultural practices and habits in Lithuania. It is conducted on a broader national scale. It covered all the municipalities as the event covered 60 municipalities across the country, which led to interactions between the locals and the immigrants, and the event lasts for around 2 hours in which the moderator also facilitated the interaction and communication between the immigrants and the local community members. These mainly held in public institutions like schools, colleges, and public libraries.

In these communication events, the immigrants who are either students or professionals who are working in Lithuania and represent both the other European countries and third-country nationals present their opinions and experiences and presents about their home country, its culture, cuisine, and cultural practices. Through these, they try to connect to the Lithuanian people, thereby trying to remove the stereotypes which impede integration. Regarding social media and normal media support for the event, the NGO is spreading the message of cultural integration through their social media networks of Facebook, Instagram, Twitter, and YouTube whereas they share the experiences of those cultural events with visuals and videos and also make short videos of the immigrant testimonies and share these through YouTube, which enables the public to have access to those events if they were not able to physically participate. It allows them to be virtually connected to the migrant testimonies, thereby molding their perception and to remove stereotypes, myths, and beliefs towards other cultures and practices. Also, regarding this, the media provides support for these events and publicizes these events and testimonies through their print and digital media platforms such as $15 \mathrm{mn}$.lt and the national radio network known as LRT in which the testimonies of the immigrants are published. It enables a broader reach for the immigrant views to a wider audience. Some of the immigrant testimonies about Lithuania are.

According to Liang Wenming, Tai Chi \& Qi Gong teacher, "If I have to choose the place to live, I would like to choose Vilnius. I feel comfortable here" (Wenming, 2019).

As per Feyza, a student from Turkey, "I started learning Lithuania, and I started speaking with people sitting in bus stations. I feel like those people have to see me not only as a Muslim girl, but as a foreigner coming to their country, respecting their country, and learning their language" (Feyza, 2019).

In the opinion of Kindness Nigness, who is from Nigeria and now working, a student and a volunteer for Caritas, "Now I am in Lithuania, and this is my home. If I left, I would miss the Lithuanian peace. In the beginning, only when I arrived in Lithuania, I felt different, lonely, frustrated, and to face racism. But as now three years here and studying at the Vilnius University and a Caritas volunteer, I boldly call Lithuania my home" (Nigness, 2018).

According to Olesia, who is working as a Ballet dancer, "Impressions in Lithuania are very warm, although the weather is cold, the atmosphere is cozier, but also the sky is bluer, even the residents are more pleasant. Here you can go down the street, and people simply smile" (Olesia, 2018). Thus from the above-stated testimonies, we can perceive the integration measures together with the integration events as the NGO covered the testimonies of those who are working and studying in Lithuania and explore on a broader geographical basis covering other European countries together with the third countries in Asia, Africa, and the Middle East. As the event covered, all the municipalities of Lithuania also enable us to have an understanding regarding the immigrants. It 
was viewed as a significant aspect, as most of the rural villages and municipalities have not seen or communicated with the immigrants because the majority of the immigrants are settled in the major towns of Lithuania, such as Vilnius, Kaunas, and Klaipeda. It is mainly due to the young nature of the country and the lack of industrial and commercial establishments in the rural regions. As the author of this paper and a participant of the project Bukim Pazistami, I visited together with the coordinator to a few rural areas, including high schools and public libraries.

I shared my experience and perception towards Lithuania and the socio-cultural, historical, and political practices of India. I find these experiences a great eye-opener as a migrant, like the local stereotypes regarding the immigrants, the migrants also formulated the stereotypes regarding the local communities. During these visits, I was able to remove these stereotypes and was able to break the stereotypes of the local communities also. About the local stereotypes towards the immigrant with an Asian name and appearance, during these events, the coordinator starts these events with a quiz with questions about the immigrant nationality, marital status, age, and occupation. From this, we can understand the stereotypes as most of the respondents stated that the immigrant is a person from either India, Sri Lanka, Nepal, and is married and having 5/6 kids and having an IT job. It shows the stereotypes about nationality, which, according to the respondents, have been shaped by the news from media and films. As an immigrant, I have the stereotype that the locals are not cordial, warm, or are interested in oriental culture. It got shattered with the love and warmness towards the Indian culture and the passion for the movies and cultural aspects. Thus, through these visits, the NGO was able to remove the stereotypes and to formulate positive perceptions in both the immigrants and the local communities.

The third advocacy measures of the NGO for immigrant integration is media orientation. Regarding the media orientation and support, the coordinator stated that the media networks such as the national radio LRT and newspapers such as $15 \mathrm{~min}$.lt support and publish the report regarding the integration event of Bukim Pazistami and share the immigrant testimonies. Also, newspapers such as $15 \mathrm{~min}$.lt, Delfi, which takes initiatives for sharing the immigrant experiences in Lithuania by writing news articles and national radio LRT program "Ryto garsai (morning sounds), which shares the immigrant perspectives and experiences. Through these measures, the media acts as a facilitator and shape positive perceptions for immigrant integration.

The final advocacy measure of the NGO for immigrant integration is the means of acquiring national and European integration funds and grants. It is facilitated by NGO Information Support foundation through which the grant "Lithuania identity - mosaic of nations," funded by EU Asylum, Migration and Integration Fund implemented for immigrant integration. The project is intended to inform society about the changes we are overcoming as a country in the global refugee crisis processes. It is mainly an information campaign, with activities combining articles in media outlets, TV broadcasts, and social media. Thus, with the above advocacy measures the NGO is actively acting as a facilitator and a link between the immigrants and locals for immigrant integration in the society.

Figure 3 shows the media activities of the NGO using the social media platform, the article analyzed the social media activities of the NGO by analyzing the Facebook post for half a year from November 1, 2018, to May 2, 2019. The analysis aims to understand the cultural activities of the NGO for the immigrant integration and cultural exchanges between the immigrants and local communities. From the analysis, it perceived that the number of Facebook post totaled 67 during the given period in which the post covered the major themes of the activities of the project, with 36 posts covering the migrant integration activities of the NGO by organizing the events in different municipalities covering educational institutions, youth centers, and public institutions. 


\section{Figure 3}

Distribution of post shared in the NGO from 01 November 2018-May 2, 2019

\section{Table 1}

Number of viewers of Facebook Post from November 1 , 2018-May 02, 2019

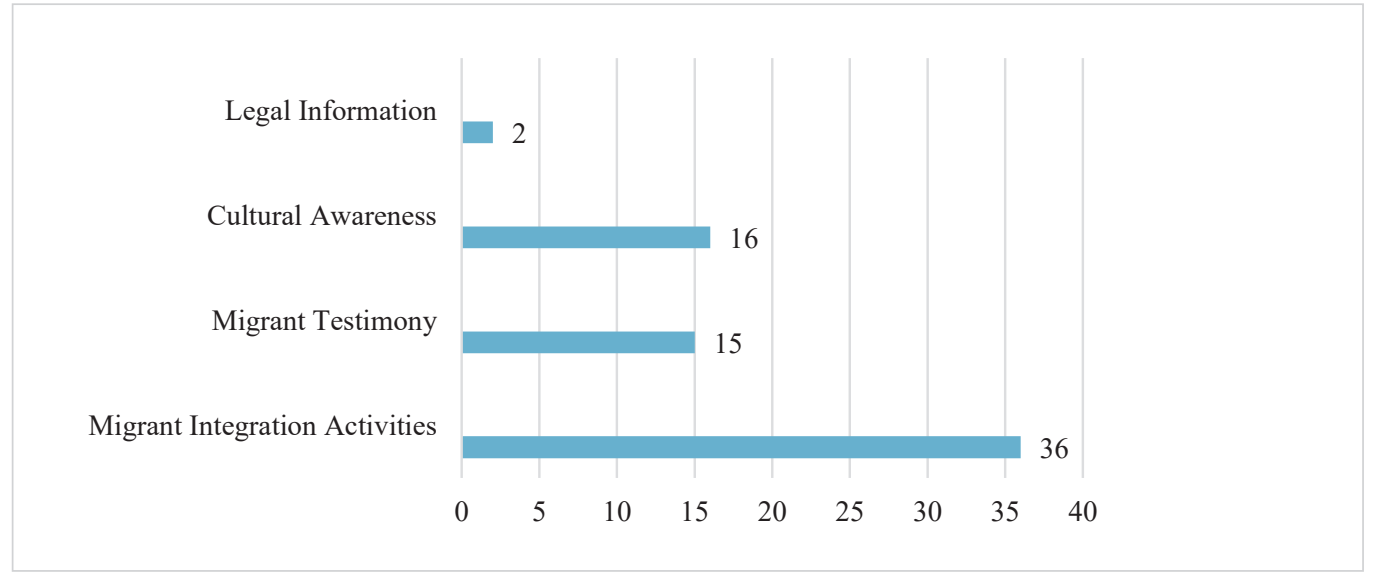

Source: Facebook page, Bukim Pazistami

Also, greater significance was given to migrant testimonies and sharing these through media and social media, especially Facebook, as this theme has been represented 15 times during the time. Other two themes which were covered are the cultural awareness in which seminars and discussions have been conducted for the immigrant communities to give an overview of the socio-cultural aspects of the country and to familiarize others with the challenges and opportunities which highlighted 16 times and the legal information regarding the residence permit and legal measures which were mentioned 2 times in the posts.

Along with the analysis of the social media activities of the NGO, it is important to explore public participation in the activities of the NGO. This was evaluated by analyzing the public following and the number of likes, shares, and significant public comments for the NGO during the given period. The Facebook page of the NGO was established in October 2017 and had around 1,082 followers for the social profile, which, according to the overall demographics and population, looks a significant number.

Table 1 depicts the public participation in the activities of the NGO as, during the taken six months of the Facebook post, there were 1,075 likes and 107 shares for the post.

\begin{tabular}{l|c|}
\hline \multicolumn{1}{|c|}{ Characteristics } & Total Numbers \\
\hline Number of likes & 1075 \\
\hline Number of shares & 107 \\
\hline
\end{tabular}

Source: Facebook page, Bukim Pazistami

Also, the article looks at the user's active participation in the NGO's Facebook activities, and it shows that unlike other NGOs in the more socially active Western countries and the United States, which have a large migrant population, the participation in Lithuania seems less vibrant. It can be mainly attributed as priorly mentioned the newly independent nature of the country and the aspect of fear of outsiders due to the Soviet occupation in the past. However, the NGO's especially the Europos Namai along with Red Cross, Caritas and Diversity Group provides the orientation to the community to remove the notions of fear and to embrace the immigrants who can facilitate as a source of community socio-cultural enrichment, which can offer a new dimension to the Lithuanian identity. It is reflected in the user participation, as the NGO was able to 
gather 1,075 likes and 107 shares for the social media posts. Also, they were able to collect some significant comments on social media posts with mixed opinions. The below-mentioned posts show the embracing approach of the public towards the events of cultural integration activities:

"Many thanks to the whole team. You are real, warm, and very vibrant, organized, and smart. Thank you on behalf of the entire community. Good luck to you until a pleasant next meeting." (Anonymous 1, 29 April 2019 Facebook, Bukim Pazistami)

"It was a great event with such kind people."

(Anonymous 2, 29 March 2019 Facebook, Bukim Pazistami)

Thus, the article comprehensively investigated the immigrant integration activities of the NGO's in society by exploring the advocacy activities of the NGO in the Lithuanian context. To understand the advocacy activities of the NGO, the article explored the qualitative content analysis using the interview from the coordinator and the analysis of the Facebook discourse. Thus, from the analysis, we were able to understand that the NGO using its advocacy and social media platform is actively facilitating immigrant integration. These measures are enabling the local communities to perceive the immigrants as a positive aspect of the society who are bringing effective workforce and human resources, vibrant cultural diversity, economic aspects, demographic dividend and who embraces the Lithuanian cultural aspects rather than to look them on the background of fear and suspicion. Therefore future research should explore the continuity of the activities of the NGO, the changing public perception of the local communities by facilitating discourse analysis, and explore the new legal and social measures envisaged by the public authorities and policymakers, which encourages further immigrant integration measures.

- The findings of the study state that measures for immigrant integration need to be viewed as a vital aspect of immigrant assimilation in society. As immigrants are people and communities who immigrate to another destination for diverse socio-political, economic, and cultural reasons, the lack of proper integration measures can lead to tensions, chaos, and struggles between them and the local communities.

- Therefore, significant measures should envisage for facilitating immigrant integration, and the NGOs can play one of the significant roles. In this regard, the NGOs through the mechanism of advocacy acts as a promoter for the amicable immigrant integration and to enhance the trust and faith of the local communities. It facilitates advocacy activities in the form of lobbying, cultural awareness, media orientation, and acquiring the national and European funds for immigrant integration activities through which it acts as a channelizing force for coordinating the activities of actors such as public, private and third sector organizations through the means of network institutionalism which reduces the conflicting nature of these actors and ensures the resource allocation for immigrant integration and assimilation.

- Thus, through these advocacy measures, the NGO channelizes the communication between the immigrants and local communities, which enhances the trust and faith among each other. These through the medium of media and communication enhances the confidence and wider public reach. It promotes the sharing of the experiences and cultural diversity, which can disrupt the preconceived notion and the stereotypes between each other.

- Thus, this article explored the role of NGOs in facilitating immigrant integration using advocacy measures in the context of Lithuania. From the analysis of the interview and the Facebook discourse, the article clearly states the advocacy measures and the mediatized communication of the NGO for the immigrant integration in Lithuania. 


\section{References}

About us | outreach.un.org.ngorelations. (n.d.). Retrieved from https://outreach.un.org/ngorelations/ content/about-us-0

Anonymous 1. Facebook: Bukim Pazistami (accessed April 29, 2019)

Anonymous 1. Facebook: Bukim Pazistami (accessed March 29, 2019)

Beyers, J. (2008). Policy issues, organisational format and the political strategies of interest organisations. West European Politics, 31(6), 1188-1211. https://doi.org/10.1080/01402380802372654

Beyers, J., Eising, R., \& Maloney, W. (2008). Researching interest group politics in Europe and elsewhere: much we study, little we know?. West European Politics, 31(6), 1103-1128. https://doi. org/10.1080/01402380802370443

Brown, L. D., \& Korten, D. C. (1989). Understanding voluntary organizations: Guidelines for donors (No. 258). The World Bank.

Brown, L. D., Khagram, S., \& Moore, M. H. (2000). MH/ Frumkin, P., Globalization, NGOs, and Multisectoral Re-lations. https://doi.org/10.2139/ssrn.253110

Būkim pažistami. (2018, November 11). Būkim pažistami! Kindness. Retrieved from https://www. youtube.com/watch?v=WeY5G7uvfTM

Būkim pažjstami. (2018b, November 11). Būkim pažistami! Olesia. Retrieved from https://www.youtube. $\mathrm{com} /$ watch? $v=J f F O j G F v 0 d E \& t=26 \mathrm{~s}$

Būkim pažistami. (2019, April 8). Būkim pažistami! Liang. Retrieved from https://www.youtube.com/ watch?v=V3GqSh4CBas

Būkim pažistami. (2019b, June 6). Būkim pažistami! Feyza. Retrieved from https://www.youtube.com/ watch?v=ukwAZAbNkVA\&t=41s

Charnovitz, S. (1996). Two centuries of participation: NGOs and international governance. Mich. J. Int'l L., 18, 183.

Douglas, T. J., \& Judge Jr, W. Q. (1995, August). Integrating the Natural Environment Into The Strategic Planning Process: An Empirical Assessment. In Academy Of Management Proceedings (Vol. 1995, No. 1, pp. 475-479). Briarcliff Manor, NY 10510: Academy of Management. https://doi.org/10.5465/ ambpp.1995.17537536
Ebrahim, A. (2005). NGOs and organizational change: Discourse, reporting, and learning. Cambridge University Press.

Ericson, R., \& Doyle, A. (1999). Globalization and the policing of protest: the case of APEC 1997. The British journal of sociology, 50(4), 589-608. https://doi. org/10.1111/j.1468-4446.1999.00589.x

Fisher, W. F. (1997). Doing good? The politics and antipolitics of NGO practices. Annual review of anthropology, 26(1), 439-464. https://doi.org/10.1146/ annurev.anthro.26.1.439

Grobman, G. M. (2002). The nonprofit handbook: Everything you need to know to start and run your nonprofit organization.

Hudson, A. (2002). Advocacy by UK-based development NGOs. Nonprofit and Voluntary Sector Quarterly, 31(3), 402-418. https://doi. org/10.1177/0899764002313005

Hulme, D., \& Edwards, M. (1997). Too close for comfort? NGOs, states and donors. St. Martin's Press. Londres. https://doi.org/10.1007/978-1-349-25253-4

Keck, M. E., \& Sikkink, K. (2014). Activists beyond borders: Advocacy networks in international politics. Cornell University Press. https://doi. org/10.7591/9780801471292

Klüver, H. (2011). The contextual nature of lobbying: Explaining lobbying success in the European Union. European Union Politics, 12(4), 483-506.https://doi. org/10.1177/1465116511413163

Kolk, A., \& Van Tulder, R. (2002). Child labor and multinational conduct: a comparison of international business and stakeholders codes. Journal of Business Ethics, 36(3), 291-301. https://doi. org/10.1023/A:1014009313508

Korten, D. C. (1990). Getting to the 21st Century. Kumarian Press.

Lewis, D. (2010). Nongovernmental organizations, definition and history. International encyclopedia of civil society, 1056-1062.

Lewis, D., \& Kanji, N. (2009). Non-governmental organizations and development. Routledge. https:// doi.org/10.4324/9780203877074

Lindenberg, M., \& Bryant, C. (2001). Going global: Transforming relief and development NGOs (p. 220). Bloomfield, CT: Kumarian Press. 
London, T., \& Hart, S. L. (2004). Reinventing strategies for emerging markets: beyond the transnational model. Journal of international business studies, 35(5), 350-370. https://doi.org/10.1057/palgrave. jibs. 8400099

Mahon, J. F., \& Waddock, S. A. (1992). Strategic issues management: An integration of issue life cycle perspectives. Business \& Society, 31(1), 19-32. https://doi.org/10.1177/000765039203100103

Malhotra, K. (2000). NGOs without aid: Beyond the global soup kitchen. Third World Quarterly, 21(4), 655-668. https://doi.org/10.1080/713701062

Marsh, D. (Ed.). (1998). Comparing policy networks (p. 53). Buckingham: Open University Press.

Meyer, C. A. (1999). The economics and politics of NGOs in Latin America. Praeger Publishers.

Minkoff, D.C. (1997) 'The sequencing of social movements', American Sociological Review 62(5): 779799. https://doi.org/10.2307/2657360

Mostashari, A. (2005). An introduction to non-governmental organizations (NGO) management. Iranian studies group at MIT, 2.

Mukasa, S. (1999). Are expatriate staff necessary in international development NGOs? A case study of an international NGO in Uganda (No. 4). Centre for civil society, London school of economics and Political Science.

Ohanyan, A. (2008). NGOs, IGOs, and the network mechanisms of post-conflict global governance in microfinance. Springer. https://doi. org/10.1057/9780230616103

Olson, M. (2009). The Logic of Collective Action: Public Goods and the Theory of Groups, Second Printing with a New Preface and Appendix (Vol. 124). Harvard University Press. https://doi.org/10.2307/j.ctvjsf3ts

Parker, A. R. (2003). Prospects for NGO collaboration with multinational enterprises. Globalization and NGOs: Transforming Business, Government, and Society, 81, 105.

Pérez-Díaz, V. (1998). The public sphere and a European civil society.

Peterson, M. J. (1992). Transnational activity, international society and world politics. Millennium, 21(3), 371-388. https://doi.org/10.1177/030582989 20210030901

Pharr, S. J. (2003). Conclusion: Targeting by an activist state: Japan as a civil society model. The state of civil society in Japan, 316-336. https://doi. org/10.1017/CB09780511550195.017

Rahman, M. (2003). Management of NGOs: A study in SAARC countries (Doctoral dissertation, Ph. D. dissertation, University of Karachi, Karachi.(Retrieved on 18 May 2011, http://eprints. hec. gov. pk/1377/1/1080. html. htm) p. 43).

Reinicke, W. H., Deng, F., Witte, J. M., Benner, T., \& Whitaker, B. (2000). Critical choices: The United Nations, networks, and the future of global governance. IDRC, Ottawa, ON, CA.

Reisel, W. D., \& Sama, L. M. (2003). The distribution of life-saving pharmaceuticals: viewing the conflict between social efficiency and economic efficiency through a social contract lens. Business and Society Review, 108(3), 365-387. https://doi. org/10.1111/1467-8594.00169

Sanderson, S. (2002). The future of conservation. Foreign Affairs, 162-173. https://doi. org/10.2307/20033275

Stromquist, N. P. (1998). NGOs in a new paradigm of civil society. Current issues in comparative education, 1(1), 1-5.

Swank, D., \& Duane, S. (2002). Global capital, political institutions, and policy change in developed welfare states. Cambridge University Press. https://doi. org/10.1017/CB09780511613371

TRENDS, S. H. F. T. (2014). Transatlantic trends: Mobility, migration and integration. Key Findings From 2014 and Selected Highlights From Transatlantic Trends and Transantantic Trends: Immıgraiton 2008, 13.

United Nations Population Division | Department of Economic and Social Affairs. (n.d.). Retrieved from https://www.un.org/en/development/desa/ population/publications/migration/migration-report-2013.asp

Vachani, S., \& Smith, N. C. (2004). Socially responsible pricing: Lessons from the pricing of AIDS drugs in developing countries. California Management Review, 47(1), 117-144. https://doi. org/10.2307/41166289

Vilain, M. (2002). Nonprofit Management-Current Challenges for Personnel Management in German Welfare Organisations. In Transforming Civil Society, Citizenship and Governance: The 3rd Sector in an Era of Global (Dis) Order. Conference Working Papers (Vol. 3, pp. 7-10). 
Whitley, R. (1999). Competing logics and units of analysis in the comparative study of economic organization: The comparative-business-systems framework in perspective. International Studies of Management \& Organization, 29(2), 113-126. https://doi.org/10.1080/00208825.1999.11656766

Willetts, P. (2002). What is a non-governmental organization?

Willetts, P. (2010). Non-governmental organizations in world politics: The construction of global governance (Vol. 49). Routledge. https://doi. org/10.4324/9780203834305
Wooten, M., \& Hoffman, A. J. (2008). Organizational fields: Past, present and future. The Sage handbook of organizational institutionalism, 1, 131-147. https://doi.org/10.4135/9781849200387.n5

Žibas, K. (2018). Mapping of social orientation: the case of Lithuania. Diversity Development Group, Lithuanian Social Research Centre. Available online: http://raccombat-project. eu/wp-content/uploads/2018/03/Mapping-Social-Orientation-LT. pdf. Žiliukaitè, R., Ramonaitè, A., Nevinskaitè, L., Beresnevičiūtè, V., \& Vinogradnaitè, I. (2006). Undiscovered power: A map of Lithuanian civil society.

\section{About the} author

\section{MURALEEDHARAN VISHNU}

\section{Master of Public Policy and Administration}

Kaunas University of Technology

\section{Fields of interests}

Public policy, political communication, migration, media studies

\section{Address}

A. Mickevičiaus 37, LT-44244 Kaunas, Lithuania,

Phone: +37069695392

E-mail: vishnuvalayil@gmail.com 